\title{
Rapidity Optimization of the Aircraft Carrier Based on the Minimum Resistance
}

\author{
WANG Yu-juan \\ College of Ship-building Engineering \\ Harbin Engineering University, HEU \\ Harbin, China \\ yj020111@163.com
}

\author{
HUANG Sheng \\ College of Ship-building Engineering \\ Harbin Engineering University, HEU \\ Harbin, China
}

\author{
Fang Xin-yue \\ College of Ship-building Engineering \\ Harbin Engineering University, HEU \\ Harbin, China \\ 83172711@163.com \\ WANG Gang \\ China Petroleum Liaohe Equipment Company \\ CPLEC \\ Panjin, China
}

\begin{abstract}
On the basis of the model of the aircraft carrier "Kitty Hawk", the designer will obtain different models through parody transformation to change its aspect $\operatorname{ratio}\left(L_{\omega} / B_{\omega}\right)$, block coefficient $\left(C_{b}\right)$ and displacement $(\Delta)$ and calculate the resistance of different models. With the principle of the optimal speed, taking an overall consideration of initial stability, seakeeping performance and the restrictions of flight deck and hangar width of the aircraft carrier, we get a new ship form and the corresponding speed. Compared the results with the parent ship, the speed of the optimized ship has increased from $32 \mathrm{kn}$ to $35 \mathrm{kn}$. The conclusion is that the rapidity of the new ship has been optimized.
\end{abstract}

Keywords-aircraft carriers; parody transformation; rapidity; initial stability; seakeeping performance

\section{INTRODUCTION}

As a highly mobile marine airfields and naval bases, aircraft carrier has received the world attention of the global navy since its creation. To seize command of the sea and air supremacy is a very important task for large aircraft carriers. And the rapidity of the aircraft carrier largely determines the status and combat mission of an aircraft carrier in the war ${ }^{[1]}$.Improving the rapidity of "Kitty Hawk" with the premise of other performance unchanged has a significance on the development of future aircraft carriers.

\section{THE INFLUENCE OF RAPIDITY BY THE ASPECT} $\operatorname{RATIO}\left(L_{\omega} / B_{\omega}\right)$ CHANGING WITH A CONSTANT DISPLACEMENT

\section{A. The Influence of Rapidity by the Aspect Ratio $\left(L_{\omega} / B_{\omega}\right)$}

For the medium and high speed ship, with the change of the length and the corresponding speed, it will get the best length $L_{o p t}$ of the lowest overall resistance under the condition of the constant displacement ${ }^{[2]}$. Increasing the length may reduce the overall resistance of the ship within the preferred length range. According to the statistics, the $L_{\omega} / B_{\omega}$ value is in the range of $7.10-8.10^{[3]}$, which can ensure the model displacement unchanged, and parody transforming the length and width of the ship is showed in the following schemes Table 1.

According to the five model schemes in table 1 , the designer calculated the resistance curve under the speed of $32 \mathrm{kn}$, as shown in Figure 1 which can conclude that the ship resistance getting smaller as $L_{\omega} / B_{\omega}$ increasing within the range of 7.20-8.10 and the constant displacement.

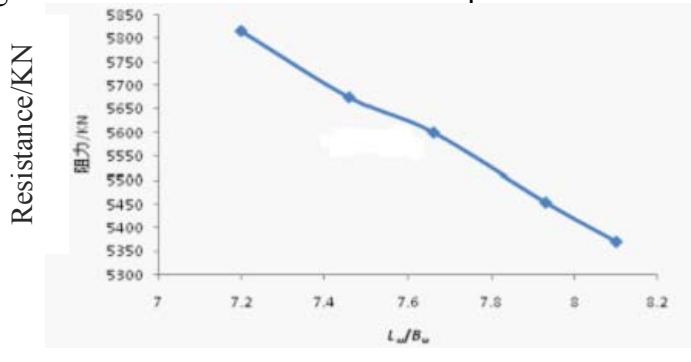

Figure 1. $L_{\omega} / B_{\omega}$ resistance curve of designed speed

\section{B. The minimum $B_{\omega}$ limitation by flight deck width}

As a special ship that can carry a large number of carrierbased aircrafts, the aircraft carrier needs the consideration of the influence on the stability, cabin layout, the aircrafts of hangar placed and the aircrafts of flight deck placed due to the change of $L_{\omega} / B_{\omega}$. Therefore, the fight deck arrangement restricts the transformation of main dimension.

The minimum waterline width and the flight deck width is relevant, the ratio of the waterline width of the foreign angled deck and the flight deck width is about $0.525^{[4]}$. The width of flight deck is determined by the landing runway width and the stopped area of the carrier. And the minimum waterline width should be determined by the width of tail landing runway.

Taking into account the tail landing runway arrangement under the navigation, the tail landing runway should be placed at least 4 folded F-18 ${ }^{[5]}$, which is showed in Figure 2. The width of folded F-18 is $8.39 \mathrm{~m}^{[6]}$. Abiding by the static park space requirements of the carrier-based aircrafts placed on the flight deck, the safe distance of the carrier-based aircrafts parked on the technology position in park area, is not less than $750 \mathrm{~mm}^{[7]}$. As for "Kitty Hawk", the width of 
the tail landing runway is $37.9 \mathrm{~m}$, and the width of the flight deck is $72.3 \mathrm{~m}$. So as for the optimized ship, the width of the flight deck is $68.3 \mathrm{~m}$ through proportionate relationships. The ratio of the waterline width and the flight deck width of "Kitty Hawk" is 0.55 . Therefore, the optimized $B_{\omega}$ is $37.2 \mathrm{~m}^{[8]}$.

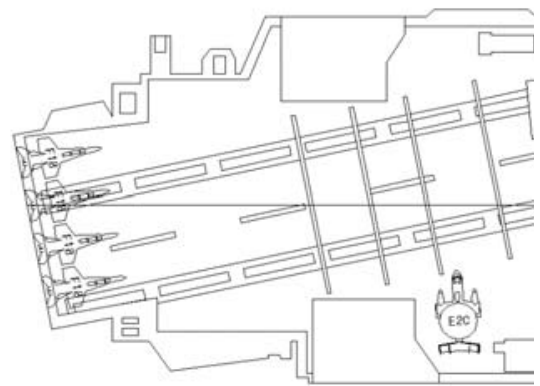

Figure 2. The aircraft arrangement on the tail landing runway under the navigation state

\section{The minimum $B_{\omega}$ restriction by the hangar width}

The width of the hangar, relating to the following factors, such as the size of the aircraft carrier and overall layout, is about $72-80 \%$ of waterline width. The increase of the width of the hangar will lead to reduce the leaving space between the side wall and the side of the hangar. However, the ratio of the hangar width and $B_{\omega}$ of Kitty Hawk is 0.827 , which has surpassed the statistical range of the hangar and the waterline width ${ }^{[9]}$.

Compared with the waterline width of the Nimitz Class aircraft carrier, the width of Kitty Hawk increased by $1.4 \mathrm{~m}$, and the hangar width only increased by $0.4 \mathrm{~m}$, so the ratio of the hangar width and the waterline width is 0.808 . The change of the aircraft positions or placing ways in hangar from Forrestal-class to Kitty Hawk-class made the hangar width of Kitty Hawk set necessarily at $32.6 \mathrm{~m}$, which is considered as the minimum waterline width. By the consideration of the rapidity and hanger placement for Kitty Hawk, the selection of the waterline length and the width is the best value. The waterline width is $39.4 \mathrm{~m}$.

TABLE I. SHIP TRANSFORMATION SCHEME WITH CONSTANT DISPLACEMENT

\begin{tabular}{|c|c|c|c|c|c|c|}
\hline scheme & transformation rule & $L_{\omega}(\mathrm{m})$ & $B_{\omega}(\mathrm{m})$ & $L_{\omega} / B_{\omega}$ & draft $(\mathrm{m})$ & $\Delta(\mathrm{t})$ \\
\hline scheme A1 & length minus 10 meters & 291.2 & 40.4 & 7.20 & 11.4 & 80500 \\
\hline scheme A2 & length minus 5 meters & 296.2 & 39.7 & 7.46 & 11.4 & 80589.4 \\
\hline scheme A3 & parent ship & 301.804 & 39.4 & 7.66 & 11.4 & 80589.4 \\
\hline scheme A4 & length plus 5 meters & 306.88 & 38.7 & 7.93 & 11.4 & 80589.4 \\
\hline scheme A5 & length plus 10 meters & 310.23 & 38.3 & 8.10 & 11.4 & 80590 \\
\hline
\end{tabular}

III. THE INFLUENCE ON RESISTANCE BY BLOCK COEFFICIENT CHANGE

The selection of the block coefficient influences so much on the resistance[10]. So the designer needs to consider the influence on overall resistance by the block coefficient variation during the aircraft carrier rapidity optimization. The model schemes are showed in Table 2.

We calculated the resistance and the powers of the five models (in Table 2) under different speed through the parody transformation and obtained the following curves (Figure 3):

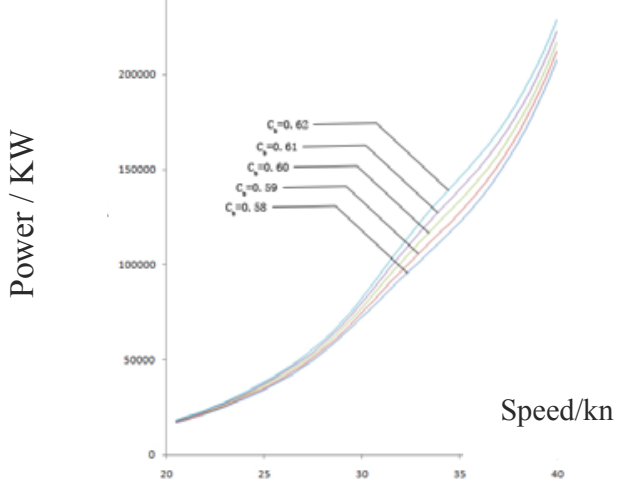

Figure 3. Speed power curves of different block coefficients
It is known from Figure 3 that the best ship resistance contributes to the minimum block coefficient. The ship resistance increased significantly with the increasing of the block coefficient.

\section{THE INFLUENCE ON THE POWER BY THE DISPLACEMENT CHANGE}

Without any consideration of the main dimension influence by the placement of the hangar and the flight deck, we obtained the different ship models by the parody transformation to the parent ship Kitty Hawk. $L_{\omega} / B_{\omega}$ is selected in the range of 7.66-7.82. And the draft is selected within 3.45-3.77 which is the range of the ratio of the waterline width and the mean draft. The schemes are shown in Table.3.

We calculated the resistance and power of the six models in Table 3 and drew power curves under different speeds.

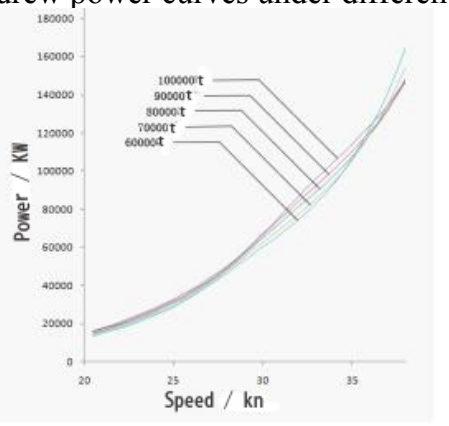


Figure 4. Speed power curve of different tonnage aircraft carrier

From the Figure 4 can be drawn the conclusion: when the speed is slightly greater than $35 \mathrm{kn}$, all the ton power curves are converging to one point. And with the increasing of speed, the power required by the small-ton class vessel is greater than the power of large-ton class ship.

TABLE II. THE SCHEME OF BLOCK COEFFICIENT VARIATION IN SAME SHIP

\begin{tabular}{|c|c|c|c|c|c|}
\hline scheme & $C_{\mathrm{b}}$ & $L_{\omega}(\mathrm{m})$ & $B_{\omega}(\mathrm{m})$ & $\operatorname{draft}(\mathrm{m})$ & $\Delta(\mathrm{t})$ \\
\hline scheme B1(parent ship) & 0.58 & 301.804 & 39.4 & 11.4 & 80589.4 \\
\hline scheme B2 & 0.59 & 301.804 & 39.4 & 11.4 & 81978.87 \\
\hline scheme B3 & 0.6 & 301.804 & 39.4 & 11.4 & 83368.35 \\
\hline scheme B4 & 0.61 & 301.804 & 39.4 & 11.4 & 84757.82 \\
\hline scheme B5 & 0.62 & 301.804 & 39.4 & 11.4 & 86147.29 \\
\hline
\end{tabular}

TABLE III. SCHEME OF DIFFERENT TON DISPLACEMENT SHIP

\begin{tabular}{|c|c|c|c|c|c|c|c|}
\hline & transformation rule & $L_{\omega} / B_{\omega}$ & $T(\mathrm{~m})$ & $L_{\omega}(\mathrm{m})$ & $B_{\omega}(\mathrm{m})$ & $\Delta(\mathrm{t})$ & $B_{\omega} / T$ \\
\hline scheme 1 & 50,000 tons & 7.66 & 10.2 & 268.1 & 35.0 & 53982 & 3.43 \\
\hline scheme 2 & 60,000 tons & 7.66 & 10.6 & 276.1 & 36.0 & 62000 & 3.40 \\
\hline scheme 3 & 70,000 tons & 7.75 & 11.0 & 290.1 & 37.4 & 73506 & 3.40 \\
\hline scheme 4 & 80,000 tons & 7.76 & 11.4 & 301.8 & 39.4 & 80589 & 3.46 \\
\hline scheme 5 & 90,000 tons & 7.77 & 11.4 & 317.2 & 40.8 & 90734 & 3.58 \\
\hline scheme 6 & 100,000 tons & 7.70 & 11.6 & 331.2 & 43.0 & 105118 & 3.70 \\
\hline
\end{tabular}

\section{PERFORMANCE ANALYSIS OF OPTIMIZED SHIP}

The best resistance performance depends on the maximum $L_{\omega} / B_{\omega}$ value within the statistical range through the analysis of main dimensions. Therefore the $L_{\omega} / B_{\omega}$ value of the optimized ship is 8.10 , that is, $L_{\omega}=8.10 B_{\omega}$ and the minimum waterline width is $39.4 \mathrm{~m}$. Increasing the draft can improve the performance of the propeller with the consideration of the rapidity. Taking the waterline width and draft ratio as 3.45 , the $B_{\omega}=3.45 T$ and the block coefficient $C_{b}$ is selected as the minimum value 0.58 within the statistical range. below:

The load displacement calculation formula is displayed

$$
\Delta=L_{\omega} \times B_{\omega} \times T \times C_{b} \times 1.025
$$

The size of molded depth reflected the freeboard size at a certain draft, so we determined that the optimized molded depth is $29.7 \mathrm{~m}$ according to the molded depth and draft ratio from statistics.

The length of the ship is $319.2 \mathrm{~m}$ (1047 feet) in the the optimized scheme. The new ship speed is between $32.4 \mathrm{kn}$ and $35.6 \mathrm{kn}$ when the new ship speed ratio is under the range from 1.0 to 1.1 . Considering the economic speed is $35 \mathrm{kn}$, which is obtained from the displacement optimization, the maximum speed of the new ship is taken as $35 \mathrm{kn}$.

The comparison of principal dimensions between the optimized ship type and the parent pattern is showed in Table 4 , and the comparison of total factors between optimized ship and parent pattern is showed in Table 5.

By checking the new ship's initial stability and seakeeping, the results are shown in Table 6.

From the Table 6: speed is optimized for the new ship, maximum speed increased from 32 to 35 knots, the displacement increased approximately by over 5,000 tons, and five aircrafts in the hangar are added, and the effectiveness of the aircraft carrier is improved. By comparison with Kitty Hawk, there is no change for the initial stability and the seakeeping.

We calculated out the ship resistance of the optimized ship. Figure 5 is the comparison chart of the power resistance curves for Kitty Hawk and the optimized ship.

TABLE IV. THE COMPARISON OF PRINCIPAL DIMENSIONS BETWEEN OPTIMIZED SHIP TYPE AND PARENT PATTERN

\begin{tabular}{|c|c|c|c|c|c|c|c|}
\hline & $L_{\omega}(\mathrm{m})$ & $B_{\omega}(\mathrm{m})$ & $T(\mathrm{~m})$ & $D(\mathrm{~m})$ & $C_{\mathrm{b}}$ & $\Delta(\mathrm{t})$ & speed $(\mathrm{kn})$ \\
\hline optimized ship & 319.2 & 39.4 & 11.4 & 29.7 & 0.58 & 85411 & 35 \\
\hline Kitty Hawk & 301.8 & 39.4 & 11.4 & 29.7 & 0.58 & 80588 & 32 \\
\hline
\end{tabular}

TABLE V. THE COMPARISON OF TOTAL FACTORS BETWEEN OPTIMIZED SHIP AND PARENT PATTERN 


\begin{tabular}{|c|c|c|c|c|}
\hline & $\begin{array}{c}\text { hangar length } \\
(\mathrm{m})\end{array}$ & $\begin{array}{c}\text { hangar width } \\
(\mathrm{m})\end{array}$ & $\begin{array}{c}\text { flight deck length } \\
(\mathrm{m})\end{array}$ & $\begin{array}{c}\text { flight deck width } \\
(\mathrm{m})\end{array}$ \\
\hline optimized ship & 238.6 & 32.6 & 330.6 & 72.3 \\
\hline Kitty Hawk & 225.6 & 32.6 & 312.6 & 72.3 \\
\hline
\end{tabular}

TABLE VI. THE COMPARISON OF ESTIMATION FORMULA RESULTS

\begin{tabular}{|c|c|c|}
\hline & Kitty Hawk & optimized ship \\
\hline Natural rolling period & $23.5(\mathrm{~s})$ & $23.5(\mathrm{~s})$ \\
\hline Heave natural period & $8.10(\mathrm{~s})$ & $8.10(\mathrm{~s})$ \\
\hline Initial metacentric height & $3.09(\mathrm{~m})$ & $3.09(\mathrm{~m})$ \\
\hline
\end{tabular}

From figure 5 we can see, when the speed of the optimized form reached in the maximum of $35 \mathrm{kn}$, the power is less than the parent form, so the new ship was optimized in the speed.

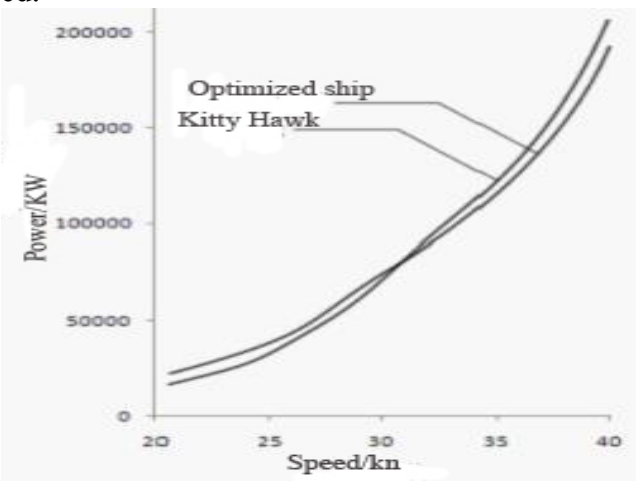

Figure 5. The comparison chat between Kitty Hawk and Optimization of ship speed power

\section{CONCLUSION}

When the displacement was constant, under the design speed, the resistance decreased with the increase of $L_{\omega} / B_{\omega}$, the speed can be optimized by increasing $L_{\omega} / B_{\omega}$ of the Kitty Hawk. But as the most special ship, some factors need to be taken into account, such as how a hangar carrier in the flight deck was put and the returns of flight deck, the limits of the designed line width as well. Through the analysis, it is thought that the minimum designed line width is 39.4 meters.
In the premise of what water length and width keeps as the same, the resistance will increase with $L_{\omega} / B_{\omega}$ increasing. By guaranteeing $L_{\omega} / B_{\omega}$ in the statistical range, transform displacement of the Kitty Hawk form, when speed is $35 \mathrm{kn}$, the influence on the change of displacement in power is very small.

\section{REFERENCES}

[1] J.Shao, K.W., Ma,Y.Y., "The Ship Technology and Design Introduction", National Defense Industry Press, Beijing, 2005.

[2] Sheng, Z.B., Liu,Y.Z., "Theory of ship", Press of Shanghai Jiaotong University, Shanghai,2003.

[3] Wang Y.S.,Yu D.H., "Illustrated Handbook of the World Aircraft Carriers",PLA Publishing Press, Beijing, 1997.

[4] Huang,S.,Meng X.Y.,Chang Xin., "Main deck extending degree optimization based on GA method", Journal of Naval University of Engineering, No. 4, 2009, pp. 34-39.

[5] Qiu J.Y., "Launch and Landing of Aircraft-carriers", Hongdu Science and Technology, No. 4, 1990, pp. 47-48.

[6] Chen B., ANG H. S., "Analysis of Take-off and Landing Characteristics of F/A-18F Carrier-based Aircraft",Journal of Nanchang Hangkong University, No. 3, 2011.

[7] Wang Q.S., "Fundamental Design Requirements for Adaptation to Aircraft Carriers", Aircraft design, No. 2, 2006, pp. 32-35.

[8] Wang Q.S., "Fundamental Design Requirements for Adaptation to Aircraft Carriers", Aircraft design, No. 2, 2005, pp. 6-10.

[9] Hu Y.L., Huang S., "Research on Design of Principal Dimension Elements of Hangar in Aircraft Carriers", Journal of Shanghai Jiaotong University, No. 8, 2012, pp. 1184-1189.

[10] Sun, S.N., "Modern Aircraft Carrier", Shanghai Popular Science Press, Shanghai (2000) 